\title{
The Practice of the Fieldbook: Facilitating and Evaluating Field-based Learning
}

\author{
C a rol B r a nd t \\ Pitzer College \\ Thom as Ma n ley \\ Pacific Northwest College of Art
}

\section{Introduction}

The relationship between experience and learning is neither modern, nor is it the exclusive province of any cultural tradition. From before Dewey and through Freire, teachers have recognized that active engagement with a problem on more than just an abstract level can lead to learning that is meaningful and long lasting. Our purpose is to elucidate a writing technique devised for experience-based study abroad programs. Known as the Fieldbook, the technique has been used with significant success on field study programs offered through Pitzer College. We believe the applied research offered in our case study contributes in critical ways to our understanding of pedagogical practices and suggests positive new directions for improving student learning.

The Fieldbook was developed in response to the assessment needs of study abroad programs that serve students not only from Pitzer College but also from over seventy other four-year baccalaureate institutions nationally. Critical aspects of its development related to the cultural immersion goals of those programs ${ }^{1}$ and the fact that traditional coursework, with its standard assessment techniques of tests, quizzes and papers was not as integral to those programs as it generally is to other study abroad models. The Fieldbook emerged from early experi- 
ments with a journal format in Parma, Italy in 1991. Thomas Manley adapted the initial concepts for the design based on a model suggested by Nancy Taylor (1991). The goal was to provide a record of student learning in the Parma program principally for home campus faculty to approbate their work. The design was later modified and improved as the result of a decade of on-site testing in other program sites. Extensive staff collaboration proved essential both to refining the technique and gaining acceptance for its use. The Fieldbook employs an integrated and diverse series of writing assignments, which students complete over the course of their study abroad semester. To date, it has figured in the educational experiences of nearly a thousand students, and has been well received by faculty at many of the institutions that send students on Pitzer programs.

Our case study addresses the application of the Fieldbook as a pedagogical and assessment tool, in an effort to understand how and why it is effective (or not). The paper is divided into two parts: in the first, specific examples of how the Fieldbook is used to engage students in certain types of learning activities are identified and discussed; in the second, aspects of the Fieldbook practice that staff and students have found either exemplary or problematic or somewhere in between are highlighted and examined.

Data is drawn from a review of ten years of student Fieldbook writing and staff (and some student) responses to a survey about its effectiveness. ${ }^{2}$ We chose an historical case study methodology because it is particularly advantageous in situations where not much research has been done and especially when the need is to identify and explain the particularities or details of a phenomenon, such as an educational innovation and why it worked or failed (Merriam, p. 34). The case study method, we believe, affords a strong and supple net for capturing and displaying the relevant details of the Fieldbook story.

\section{Part One: The Fieldbook as Pedagogical and Assessment Tool}

One might expect to find a significant amount of writing about pedagogy in the literature on study abroad, given its educational nature. This unfortunately has not been the case, and much of what does exist revolves 
around the teaching and learning of foreign languages and the cultural learning that coincides with those activities. Two exceptions are to be found in the work of Nancy Taylor (1991) and Ken Wagner and Tony Magistrale (1995). As noted, Taylor's work directly informed a precursor of the Fieldbook, the Parma journal, and the book by Wagner and Magistrale lays out a design - the analytical notebook - for a writing system that has some overlap with the Fieldbook in terms of philosophy, learning goals and structure.

The analytical notebook and the Fieldbook have in common a constructivist orientation and the goal of encouraging students to think about and relate what they have learned from lectures and readings in classes to information derived from out-of-classroom experiences. Serving as a record of experiences and a space for honing interpretation and analysis, the notebook is meant to promote the creation of new knowledge and the practice of writing as a skill.

Unlike traditional diaries or journals, which often stay in the realm of private writing and may not be designed to help students respond synchronously and constructivistically to particular elements of their environments, and unlike either the travel journal or the analytical notebook, the Fieldbook offers an integrated, structured and purposive approach to writing and learning in the field study setting.

The four major sections of the Fieldbook, and their purposes, are: Letters Home, Stories, Focus Questions, and Design Your Own (DYO). Letters Home describe in rich detail the places, people, feelings, and ideas encountered at various stages of the field experience, and students write four to five letters of 1,250-2,000 words each per semester program. Stories relate, in a narrative mode, true or fictional accounts revealing new facets of the designated culture or subculture, and four to six stories of 750 to 1,250 words each per semester program are required. Focus Questions call for expository responses to complex issues and questions posed at critical junctures during the program which demonstrate the ability to synthesize multiple viewpoints derived from readings, interviews, lectures, and first-hand experience. Four to six essays of 1,250-2,000 words each per semester program are required. Finally, Design Your Own (DYO) entries permit the writer to choose a creative mode of communication-poetry, drawing, photography, or one of the styles used elsewhere in the Fieldbook-through 
which to explore a dimension of the culture or subject being studied. Students write four to six assignments (length determined by the medium) per semester program.

Because it is tailored to the students' experiences, the Fieldbook can be fitted optimally around different program structures and learning environments. Fieldbooks are evaluated by on-site program staff members, who review and hold discussions around selected assignments, assessing them according to established quantitative and qualitative criteria.

Assignments are graded and quickly returned with the reader's comments. In keeping with the idea that writing helps learners generate knowledge as well as communicate it (Fulwiler 1988), rewriting of Fieldbook entries is permitted and encouraged. In this sense, the Fieldbook allows students to discover, create, and formulate ideas; receive near immediate response in the form of written comments; rethink ideas or generate new ones; and present a revised entry that demonstrates achievement of the performance-based assessment criteria. As the Fieldbook evolved, rewriting was increasingly recognized as an essential component of the writing/learning process.

We have identified nine modalities of learning exhibited through the Fieldbook reflective of the principles of constructivist teaching we believe are important to creating effective intercultural learning. The following sections describe each of these areas in detail.

\section{Area One: Active Engagement with the Subject Matter}

The Fieldbook provides focus by engaging students actively with the subject matter. Specific guidelines are presented for each of the four sections to help in the organization of ideas, and subtopics are often suggested for each assignment. For example, in Pitzer's 1996 China program, where American students shared rooms with Chinese students, suggestions for the second Letter Home assignment lead the writer to make observations about what is being experienced and encourage comparisons, which may extend the boundaries of that experience. In contrasting living conditions of international students and "regular Chinese students," American students are asked to explore the mechanics of eight-to-a-room living and thus engage in a new intercultural aware- 
Frontiers: The Interdisciplinary Journal of Study Abroad

ness. ${ }^{3}$ One female student, after describing in some detail the relatively plush conditions of her own "foreigners" dormitory, wrote to a friend in her Letter Home:

Why am I so amazed by the accommodations described above? What appears to be just normal living conditions turned out to be a privilege that is enjoyed by few people here at ECNU. ${ }^{4}$ The luxuries of space, heat, light after 11 pm, privacy, hot water, and a private bathroom are non-existent in the regular student dorms. The students' dorms are more like prison cells than a dormitory. Most of the dorms are quite old. I could not believe my eyes when I visited my (Chinese) roommate's (former\} dormitory. The building has 6 floors, 40 rooms/floor and 8 students/ room, which means about 1900 students/dorm. (My college has less than that number of students.) Each floor has a shower room, but it is only used during extremely hot weather because there is only cold water in the showers. During winter, all students at ECNU resort to the four public baths (2 female and 2 male), which have about 30 showerheads per bathroom. Inside the dorm, there are no (toilets), so students have to go to extremely dirty and unsanitary public outhouses. ${ }^{5}$ There are also no washing machines, so students wash their clothes by hand in a washing room located on every floor. The ballways are dark and gloomy-no overhead lights, no carpets. Along the side... damp clothes are hung to be dried. It's weird that everyone on the ball knows what kind of underwear, socks, etc. another person has.

Focus Questions also engage students actively with subject matter by valuing a variety of viewpoints as part of interpretation and analysis. Consequently, Focus Questions frequently are constructed so that students interview people in the community to harvest information and perspectives, to synthesize with what they have encountered in readings and lectures. A Focus Question on religion used for the program in Parma, Italy illustrates:

Parma, like most cities in Italy, has many churches-52 at last count; yet Parma is not known as a city of churchgoers. How does one account for this apparent anomaly? Is Parma typical of other communities in Italy in this respect? Using specific examples drawn from interviews with Parmigiani of three different age groups, senior, middle-aged, 
young adult, or teen, as well as supporting information from the lectures and readings on this topic, write about the role of religion in Parma. (Suggestions: Attend mass at several churches, noting who is in attendance. Write a set of interview questions to elicit information on direct and indirect aspects of religion in people's lives. Write down your assumptions before starting and find ways to challenge them. Note the presence of religious items in homes and other secular places.)

Here, students must weave the opinions of at least three people into their responses, and are given other suggestions to involve them directly and personally with the topic and host culture.

In one response to this focus question, a student observes a generation gap in church attendance:

I attended Sunday mass at Santa Maria della Steccata. Located in the center of town, the church was well attended, but mainly by senior citizens and tourists who would wander in and out during the services. I saw very few families and no young adults, either alone or with friends.

Area Two: Arousing Student Curiosity about Multiple Subjects

The Fieldbook awakens students' curiosity about what is being studied even when it isn't a topic that relates directly to their field of interest. This results from an emphasis on active learning, from the range of issues addressed, and from its flexibility of design. Individual student interest, even within majors, can vary greatly. Fieldbook assignments and styles accommodate differences by offering multiple opportunities for reflection and interaction. Focus Questions allow, and at times demand, interdisciplinary responses and touch on many subjects, including politics, sociology, religion, economics, anthropology, history, environmental studies, and philosophy, among others.

Focus Questions are developed by program staff with input from former students and in consultation with home campus faculty, one of several ways in which faculty are involved. The questions flow from themes and interests recurrent in the questions students tend to pose over the course of a program as they encounter different aspects of the host culture 
and find themselves more deeply immersed in it. Because the questions anticipate certain cross-cultural student experiences, they serve to heighten awareness and curiosity. In each program and with each Fieldbook, careful consideration is given to the order and timing of assignments, to avoid creating unachievable demands that will frustrate students. Rather, the goal is to stimulate curiosity by scheduling assignments and posing questions at times when students are better able answer them. For example, a question on the national identity of Italians is posed towards the end of the semester:

Italians have traditionally shown greater pride and loyalty to their local region than to Italy in a national sense. Explore this attitude of local pride with the people you come in contact with in Parma and Modena. Also, try to observe and analyze changes, if any, about attitudes toward Italy as a nation, in light of the important political events that have been occurring in recent times. Is there a new awareness of Italian identity as a member of the European community? Is there a sense of national pride thanks to the growth of new political parties? Or are Italians uneasy about the course their country is taking and the image it projects to the world?

\section{Area Three: The Opportunity to Record Experiences and Reflect upon Them}

Whereas stand-alone tests, essays, and papers tend to conflate what a student has learned, the portfolio style of the Fieldbook operates to track the learning over the program period and provides regular opportunities for recording and reflecting on experiences. These are then preserved as reference points for later consideration. Below, a student comments in a Letter Home to her parents about the progress she has made with Italian and her intercultural understanding:

Although (my) improvement may sound quite minor, it really is a buge step between coming to Italy and knowing nothing other than "ciao" and being able to navigate through local life all by myself.

Invariably, students are pleased to have the Fieldbook as a document of their experiences, even when they initially doubted the usefulness of the 


\section{Carol Brandt and Thomas Manley}

technique. "I hated the fieldbooks," wrote one Zimbabwe program participant on an evaluation at the end of the program, "but I was grateful to be forced, especially to write Stories. A real growing experience for me." And from another student who would later join the program staff: "I now treasure my own Fieldbook as a wonderful record of the experience I had as a student" (Fieldbook Survey (FBS), Item 7). And, from a staff member on the Turkey program:

I can see more and more how central the Fieldbook is to belping students meaningfully reflect on and integrate what they are learning. It also provides us (the staff) a way to measure what they are learning and is a record of what we have accomplished together over the semester. (FBS, Item 7)

\section{Area Four: Thinking and Writing as a Process}

Through the Fieldbook technique, students are encouraged to think and write as a process in which they describe, question, associate, analyze, and synthesize. The writing assignments may vary in what they require, with the Letters Home emphasizing disciplined observation and rich description and the Focus Questions being more analytical, for example, but in the aggregate, the Fieldbook demands a wide complement of cognitive skills. Because of the high degree of articulation with experience and the guided nature of its structure, the Fieldbook is more than a test of what is being learned. For many students it is an orientation to the critical notion that writing is a tool for expressing and furthering thought. A former student notes:

In writing my own Fieldbook, I learned a lot of critical analysis skills, including bow to synthesize information gathered from informal conversations and interviews into a formal summary of my current perception of a particular aspect of a culture or society. ... The intensive writing expectations belped me build a lot of confidence in my ability to write and actually did make me a much better writer. I learned a lot about how much writing can belp you process an experience and gained respect for writing as a learning tool. (FBS, Items 1 and 2) 
Area Five: Identifying the Known and the Unknown

The Fieldbook gives students time and occasion to identify what they know and do not know about a subject. This is true specifically when students undertake to respond to a focus question that requires synthesis of lecture, reading, and interview information. Also, since guidelines with Focus Questions and a schedule for completing assignments can be made available at the start of a program, students can be alerted to the scope of issues and subjects to be covered. Moreover, the type and timing of Fieldbook assignments are conducive to pre-program preparation, where students can be asked to familiarize themselves with the technique by writing their first Letter Home on preconceptions and concerns before departure and submitting the assignment shortly after arrival.

\section{Area Six: Uncovering Information and Insights}

The Fieldbook helps students uncover information and insights ordinary journal writing often misses. "They realize they need more information before making conclusions," wrote Claudio Feboli, the academic coordinator of the Parma program (FBS, Item 10). From Zimbabwe, Nadine Francis, who was closely involved in developing the Fieldbook, observed:

Unlike journals, which I think tend to be rather unfocused, overly personal, full of stream-of-consciousness... the Fieldbook pushed students to write, rewrite and barrel through a range of questions and issues that they might not have opted to address on their own. (FBS, Item 2)

The process of uncovering seems to be most evident with Stories, which reveal connections among ideas, events, or people that would remain otherwise hidden. Kathryn Bourgeois Asan, the program coordinator in Turkey, writes:

At first, many students are uncomfortable with this kind (narrative) of writing and it takes them awbile to find their 'voice,' but every student at least comes up with a wonderful story that reveals trials, tribulations and joy of learning and experiencing themselves in another culture. (FBS, Item 8) 
Area Seven: Preparation for Discussion of Topics

Preparation to discuss specific topics and issues arises both from the writing-to-learn approach upon which the technique is based and from the fact that half of the assignments (Letters Home and Focus Questions) are keyed to specific content areas of the program. An added benefit derives from the commonality of student experiences (home stays, struggles with language learning, etc.), which render the task of initiating discussions much easier. Zimbabwe was one of the first sites to incorporate student discussions successfully:

In early 1996, we added bi-weekly discussion sessions around the Fieldbook topics, which enabled students to read and share their work with one another and deepen their understanding of the issues at hand. For many discussions, we invited special guests or outside facilitators who would provide alternative perspectives on the students' interpretations. (FBS, Item 6)

Area Eight: Unifying Experiential and Theoretical Knowledge

The Fieldbook helps unify experiential and theoretical knowledge, thus increasing student ability to make connections and construct or reinterpret meanings. Focus Questions, with their emphasis on the synthesis of personal observation, direct experience, lectures, readings, interviews, or other interactions with members of the host culture are designed with this purpose in mind. A question from the Turkey Fieldbook, which builds on another program exercise the students undertook in the first few weeks of their stay in a rural village located 75 kilometers outside of Ankara, demonstrates this:

Using the Life History Analysis you've completed in the village, describe the founding, development and transformation of Mahmutoglan through the eyes of the person/people you've interviewed. Bringing in information from readings and lectures, discuss how these changes parallel transformations in Turkish society as a whole.

The directors of the Venezuela program have seen in the Fieldbook 
a capacity to help students "link experience to real learning," which, they say, "is empowering, and also a good life skill to have" (FBS, Item 10). A student on the Parma program demonstrates this linkage between her own experiences and what she has read and heard from others in her response to the national identity question, already presented. After describing her travels in the southern area of Calabria, she writes:

In the three full months that I've been in Italy, I have had experiences that indicate (a) friction between regionalism and nationalism. I've observed that first of all, there is a division between Northern Italy and Southern Italy. What is considered the North, the South and the line that geographically divides the two sections of the country seems to be a very relative concept. Romans may consider themselves as being a part of the Northern regions, however, Milanese may not agree with that. However relative this dividing line seems to be, the concept of il Nord and il Sud definitely exists in every Italian mind. Paul Hoffman, in That Fine Italian Hand, states that the Northern Italy and Southern Italy' 'are in fact two distinct cultures and societies that have much in common but are also divided by many things.'

\section{Area Nine: Encourages Student Responsibility for Learning}

The Fieldbook encourages students to assume responsibility for their learning in ways that are accountable. Opportunities for demonstrating what is being learned are regular and consequent. Students are given the chance to rewrite assignments any number of times in order to improve their grade. Clear deadlines are set for each assignment and are noted in the program's master schedule and often in the calendar of assignments, which accompanies the Fieldbook guidelines.

\section{Part Two: Strengths and Weaknesses of the Fieldbook Technique}

The Fieldbook clearly has broad utility as a tool for furthering and assessing learning. However, based on feedback gathered from staff and students, certain aspects of the technique have worked better than others. 
Necessary adjustments are made each semester and at staff retreats, held every two years, fuller evaluation of the Fieldbook has permitted more extensive improvements. The information derived from these conferences and the survey of staff and students mentioned in the introduction form the main basis for the discussion that follows.

\section{Strengths and Assets in the Practice of the Fieldbook}

Overall, those who have used the Fieldbook either as teachers, students or evaluators seem to affirm its value as a device designed to facilitate and assess learning in the study abroad context. That there is a fundamental concordance among these different constituents of the technique is, in a sense, a triangulation of the general claim that has been made for the Fieldbook: that it effectively promotes and evaluates student learning in intercultural settings.

From the student point of view, while some participants expressed dissatisfaction with the Fieldbook, especially during the early years of its development, according to end-of-program interviews with staff and submitted program evaluations, almost all that used the Fieldbook found it ultimately to be a central enhancement to learning. We have cited several testimonies to this effect in the previous section, but another, which speaks to the lasting effect engendered by the Fieldbook, may be useful:

Not only did the Fieldbook serve as a documentation of my time spent in Parma, it also allowed me to follow my growth as an individual as I processed the variety of components, which made up the whole Fieldbook. There were a number of assignments that required interaction with my host family to be able to complete them. This was extremely helpful in developing a lasting relationship. I am still in touch with my host family and my first experience with them was in 1993. (FSR, Item 1)

As for staff, 13 of 15 who responded to the survey question which asked them to rate the Fieldbook's value on a scale of 1 to 7 (with seven being highest) against other forms of academic assessment, rated it six or seven. Staff member Lisa Ferrante-Perrone, recalling her own study abroad experience on a non-Pitzer program, places the Fieldbook in a comparative context: 
Frontiers: The Interdisciplinary Journal of Study Abroad

While living in Florence for a year... I experienced firsthand the importance of cultural immersion as part of the process of intercultural education and understanding. We had no Fieldbook equivalent as part of our program, and as I compare my experience to that of Pitzer students, I believe that the presence of the Fieldbook helped them learn more about Italy in a shorter period of time (even if they didn't speak Italian (when they first arrived)). ${ }^{6}$ (FBS, Item 3)

She continues in her summary by saying:

The value of the Fieldbook, to me, is that it forces a student to pinpoint episodes during the course of his or her time abroad, and then develop these episodes into tangible, creative documentaries, allowing him or her to digest and absorb the realities of the host culture through observation, comparison and contemplation. (FBS, Parma, Item 3)

Thus, beyond its power to help engage students generally as learners, the Fieldbook, through its structure and assignments, can cue them at critical junctures or episodes, helping them gain perspectives that shift their thinking.

The director of the Parma program, Franca Feboli, related two examples of such perspective shifts, which she attributed to specific, welltimed, Fieldbook assignments. In one instance, a student who had wished to study on a program in Florence, but had been directed to Parma by her adviser, arrived in Italy "dreaming of Florence and disliking Parma." Yet after the program study trip to Florence and a Fieldbook essay on "Being a Tourist versus Being a Student in Italy," the student's viewpoint on the value of living in a smaller, more accessible community like Parma had completely changed (FBS, Item 1). Another student had complained about the lack of religious diversity in Italy, and specifically about the lack of a non-Catholic church nearby that she might attend. The Focus Question assignment on Parma as a City of Churches, previously cited, and in particular a conversation with a parish priest, helped this student to see the issue differently and to appreciate the pervasive hold that Catholicism had exerted on Italian culture (FBS, Item 1).

Not infrequently, these changes in student perspective take on the character of a personal epiphany. In Nepal, a student elected to write about a "critical incident" in which she had to grapple with the death of 
a relative in her Nepali host family early on in the program when her language skills were still quite limited. Her inability to express more than "sadness" made her feel isolated from the family. Through writing about the incident, however, she came to realize that her perceptions were egocentric and ethnocentric, being based neither on understanding of how her family felt nor on how mourning rituals were conducted in a Hindu society (FBS, Item 1). The Focus Question on race for the Zimbabwe Fieldbook asks students, based on their personal experiences on the program, to react to Steve Biko's contention that "no matter what a white man does, the color of his skin - his passport of privilege - will always put him miles ahead of a black man," thus rendering him a "part of the oppressor camp." Kebokile Dengu-Zvobgo, director of the program, tells of a student who objected to the assignment, but eventually wrote a compelling essay in which he confronted his own prejudices. "This was a very painful process," she said, "leading to personal growth and development" for the student (FBS, Item 1).

The Fieldbook was at other times a vehicle for students' creativity and imagination. To assist in bringing a fresh and humorous perspective to a Stories assignment, one student in Italy enlisted a hand puppet that she carried everywhere with her as a narrator. Another student used his DYO assignments to write a play about his Italian host family. One Zimbabwe program student, after noticing the scarcity of children's books written in local languages, decided to write and illustrate a story in Shona. Poetry, music, photography, folk tales, herbal medicine remedies, tea leaf fortune telling, drawing, and dance choreography are other examples of creativity that students brought to their assignments.

But perhaps above all else, staff who have used the Fieldbook have commented on its effectiveness as a tool for engaging students more thoughtfully in the host culture. They see the technique working to facilitate such engagement in several ways: first, by helping the students to become more conscious of their "preconceptions, biases and the immersion process" in general; second, by nudging them into learning spaces that they might not ordinarily enter; and, third, by opening a communicative dialogue with staff about both the particularities and overall direction of an individual student's experiences and learning. Speaking to the last point, Francis from the Zimbabwe program remarked: 
In some cases, I felt as if the Fieldbook became one long conversation between student and facilitator, and I took pride in seeing students improve their writing and analytical skills, and perhaps more importantly, learn to approach issues with added maturity and complexity. (FBS, Item 2)

Bourgeois Asan, the Turkey program coordinator, takes the point further:

Writing in the Fieldbook acts like a dialogue between (us, the staff) and the students, the students and the culture, the students and their struggle with cultural immersion. It also belps students to fine-tune their observations, take all experiences seriously as a learning opportunity and to be more self-critical and reflective about how they are dealing with immersion. It also gives us a chance to follow the student's emotions, adaptation, and learning process in order to better belp them through this experience. (FBS, Item 3)

Taken as a body of work over a semester, a year or several years, the Fieldbooks have informed staff in the field and in Claremont about the effectiveness of programs in meeting students' educational needs, and has provided a rich source of feedback for improvement and formative evolution.

By and large, the Fieldbook has strengthened the field staff of Pitzer's External Studies in their capacities as teacher/learner and in enhancing their understanding of intercultural education. The focused structure of the technique helped them facilitate the intensive, experiential learning demands that programs placed on students, providing "an inside view of how students are conceptualizing the experience" and allowing "us to respond to real vs. imagined student needs and desires" (FBS, Item 2). Several staff members who have gone on to other teaching positions noted that they have modified the Fieldbook technique for use in language classrooms.

For others, especially those whose own cultural orientation was toward a more formal/traditional style of education, working with the Fieldbook (and the cultural immersion model) has led them to reconsider how students learn and how teachers teach. Claudio Feboli, from the Parma program, who has also taught for many years in a local classical liceo reflected: 
In my opinion the (Fieldbook) stresses the necessity to think and in this way I had to examine my own approach ... I have realized how important it is also in my teaching experience to Italian students to help them how to learn from experience, to be critical towards what is given for granted, to try to understand the reasons of their own attitude. (FBS, Item 2, emphasis added)

The director of the Pitzer in China program, Xiao Mei Wang, saw the sometimes personal nature of writing in the Fieldbook as a means of developing a rapport with her students, which might give her better insights into their thinking and in turn "makes a teacher a student, hence a better teacher" (FBS, Item 2). For Zimbabwe program director, DenguZvobgo, reading the student Fieldbook work allowed her to value the "internal logic in a perspective that I do not hold and still give the student high marks. When I started, I tended to argue with the paper and penalize [it]. I have learned from student worldviews," she goes on, "which are different from mine" (FBS, Item 2).

With respect to intercultural education, the Fieldbook gives students and teachers a different epistemological lens. Zimbabwe staff member Batsirai Chidzodzo - a graduate from that country's British-style national university - sees this as an important departure from the standard academic repertoire:

One of (the Fieldbook's) strengths is that it acknowledges participants
as knowers with valid data to contribute to the discourse ... (it is
inclusive off resources (people at all levels) that 'traditional' scholars
wouldn't think of utilizing, and with amazing outcomes that are
equally if not more valid. The (Fieldbook), because it reaches out to
people, facilitates the formation of mutually beneficial relationships
between the students and their communities, which is very central to
intercultural education. (FBS, Item 3)

Further, through the Fieldbook, staff have the opportunity to read a student's interpretations of local culture, and as the Rodriguezes, directors of Pitzer's Venezuela program, underscored, those interpretations "frequently vary drastically from our own," and make us aware of the role of our individual backgrounds and contexts in determining what we see in a new culture (FBS, Item 3). 
Writing that is captured in the Fieldbook, therefore, might be said to function as a two-sided mirror reflecting for both the student and teacher changes in awareness of culture-their own and the other's. As Claudio Feboli admitted, "it is more difficult to be objective and critical towards one's own culture than towards another," but the dialogue the Fieldbook establishes between writer and reader raises the self-consciousness of both parties. Francis summarizes nicely the knotty process of learning about culture through immersion experiences and the role of the Fieldbook:

Working with the Fieldbook reinforced my belief that it is extraordinary difficult to immerse oneself in another culture. The entries were written proof that cultural immersion is messy, complicated, tiresome, frustrating, joyous, illuminating and life changing. And it is almost always very, very hard. (FBS, Item 3)

Challenges and Issues in the Practice of the Fieldbook

We have seen the value of the Fieldbook as a tool that students and educators have used to further learning, especially in reference to intercultural education. But, in part precisely because cultural immersion is "very hard" and complex, it should not be surprising that in applying the Fieldbook as a pedagogical device, a range of issues and problems have been encountered along the way. A significant part of the Fieldbook's development, in fact, has had to do with addressing weaknesses, perceived and real, in order to strengthen the technique. In some cases, the adjustments we made produced the desired outcomes, but in other instances, problems remained persistent or new challenges emerged. Included in the latter category are matters related to: (1) the comparative effectiveness of the different assignments; (2) grading and evaluation; (3) student writing skills; (4) cultural appropriateness; and (5) student-centeredness and empowerment in the development/execution of assignments. Each issue may be treated with some independence, but it is important to keep in mind that they are nevertheless interconnected. The remainder of the paper will examine and discuss these aspects of the Fieldbook experience. 
(1) Feedback on the Comparative Effectiveness of Assignments

As we have seen, the multiple writing styles that the Fieldbook utilizes have several heuristic purposes. These include helping students to sharpen their observational skills through descriptive writing, their analytical and critical thinking skills through expository writing, their abilities to relate events in a narrative mode, and their use of creative thinking (possibly expressed through writing, but other means are possible) and expression through the DYO assignments. In theory, this mix would seem to correspond well with the learning opportunities most students encounter in cultural immersion programs. Further, it seemed to allow for a combination of academic and non-academic writing, which we thought would support different cognitive and affective kinds of learning. If we had had to guess, we would have predicted that some of the assignments, notably the Stories and DYOs, would have been more popular than others across the board with students (and for different reasons, with staff). And we would have been wrong.

Unquestionably the single most successful assignment from the staff's point of view has been the Focus Questions. For every program, these questions seem to be "the hub of the Fieldbook," helping students "to interrogate" areas of their experience that they might not normally plumb, or at least not to the extent that the assignment requires (FBS, Item 8). In the Parma program, Focus Questions, which nowadays are called "thesis driven essays," are seen as more integrative of what is being learned because they ask students to connect their experiences to a cultural context with its own history and traditions. Students put more effort into responding to this part of the Fieldbook and staff sees a better overall result in quality, although one person thought this might be the case because students are more familiar with expository writing (FBS, Item 8).

And if students invest the most time answering Focus Questions, staff likewise spend the most time developing them to maximize student learning synergistically throughout the various components of the program (e.g., home stays, language study, etc.). According to DenguZvobgo this is time consuming because questions need to be structured in "such a way that the students are ready to tackle subjects as they come."

Problem areas for the Focus Questions are twofold. Although they 
are intended to be holistic in drawing information from multiple sources, they have worked less well in getting students to incorporate ideas from readings and lectures. Staff members from several countries noted this as a weakness. "I never felt that the Fieldbook was effective in assessing how much reading students had done for the core course," wrote one staff member (FBS, Item 1). The compilation of program readers in the late 1990's was an attempt to remedy the problem, but it has not been entirely successful. The same staff member speculated that a reason for the lack of attention to readings, however, might have been an emphasis placed on "including information from interviews (or informal conversations)" (FBS, Item 1). Given the cultural immersion goal of the programs, the added focus on "field data" is probably to be expected.

A second concern with the Focus Questions deals with the development of the questions themselves. The devising of questions is essentially a teacher-driven process and, as such, reflects a fairly traditional educational approach. We will discuss this in greater detail below in addressing the Fieldbook's student-centeredness or lack thereof. For now it should be said that a number of those who have used the Fieldbook have thought that Focus Questions, in particular, should be regularly returned to student interests/needs and that giving students a more direct role in posing at least some of the questions would enhance learning:

Students have voiced the need to have a design-your-own kind of option within the Focus Questions section that will allow them to write something they really like and central to their very individual experience. This semester one of the students had wanted to write on parenting in Botswana ${ }^{7}$ for instance, because of how that played out in her Gaborone homestay. (FBS, Item 8)

There is less of a consensus about the comparative effectiveness of Letters Home and Stories. Although more readers enjoyed the Stories per se, most reported the form to be the one that students found difficult to grasp, often getting caught up in their own narratives and missing the cultural forest for the creative trees. For example, Claudio Feboli commented that students at times get so involved in spinning an interesting tale that they forget to relate to anything about Italian culture!

Some program staff tackled the problem of making Stories more effective by creating guidelines and workshops to help with story writing. 
This was done in Venezuela, but without ultimate success, leading to the virtual abandonment of the assignment. Other sites, however, have maintained, if not altered, the assignment. In Nepal, to get around the objections about academic versus creative writing and to keep the focus of the assignment more clearly on uncovering culture, Stories are handled as critical cross-cultural incidents that students must relate and explicate. There the form has become quite popular.

In contrast with Stories, Letters Home are not difficult for students to grasp as a form and to find value in. Indeed, a few staff members felt that the letters were nearly as critical as the Focus Questions, giving chronological structure to the program, as they are sequenced at the beginning middle and end, and revealing personal and intellectual change on the part of the writer and his/her perceptions. Compared to the Stories and Focus Questions, another staff member thought the Letters Home, though descriptive and interesting, were not as intellectually challenging as Stories and Focus Questions. Dengu-Zvobgo's view differed, however. She sees an affective value to the assignment and noted the letters are welcomed by those who receive them, especially parents, from whom she has received compliments on the assignment:

(The) letter tends to explore emotions and growth in a way that the other components do not get to. It is possible for Stories and even the Focus Questions to be heady and 'academic' but the letter tends to be bolistic and pedestrian in a positive sense. (FBS, Item 8)

Of all the Fieldbook sections, the Design Your Own (DYO) feature was least effective in staff eyes as a tool for encouraging student learning or evaluating it. "I have found the DYO section to be the least meaningful or integrated component of the Fieldbook," commented Bourgeois Asan. "Students tend to just see this as something that needs to get done, a piece of fluff" (FBS, Item 8).

Yet others, while not singling out the DYO as one of the more successful Fieldbook elements, choose to take a more holistic view. Jessica Samuelson, a former student and program assistant in Parma, wrote:

For me the most successful elements of the Fieldbook are the ones that allow students to push their thinking. This can be true for all aspects of the Fieldbook, although it depends on the student. Having a vari- 
ety of styles of assignments is essential to touch all of the different students' abilities. (FBS, Item 8)

Chidzodzo, in Zimbabwe, shared the sentiment, arguing that each assignment contributed different things to the Fieldbook's tool bag, while giving the students greater leeway in how they elect to address different issues (FBS, Item 8). For similar reasons, Dengu-Zvobgo also regards DYOs as important to the Fieldbook:

Here students have a chance to pursue a subject of choice and these are often excellent. One student this semester has done a booklet in Setswana, with pictures that are of Botswana. This is an assignment that ends up as social responsibility. The student saw that the primary booklets had pictures of people who did not look like the readers and decided, in a small way, to address this need. (FBS, Item 8)

\section{(2) Grading and Evaluation}

To say that there was often tension between staff and students around the assignment of grades is to put it mildly. The Fieldbook was developed primarily as an evaluation tool, designed to assess the educational activities of study abroad programs that were experiential in nature and not easily measured by traditional methods of academic evaluation. In some programs the Fieldbook represented nearly $50 \%$ of a student's final grade for the core course, an obvious sign that the program considered it serious business. Students responded, not surprisingly, by scrutinizing and questioning the criteria used to assess the assignments. They recognized, perhaps from the beginning and certainly before many of us did, that the Fieldbook was "high stakes" writing, to use writing guru Peter Elbow's (2000) term.

Students saw as well that the Fieldbook was aimed at getting them to think about experiences, thoughts and feelings that were ordinarily not part of the academic venture. For some, both students and staff, this blurred the boundary between what they had regarded as private and public domains of education and made the matter of evaluation and grading, which can be problematic even in the seemingly less ambiguous light of conventional courses, more complex. The "personal" nature of Fieldbook 
writing figured in many disagreements that staff had with students about grades for particular assignments, especially in its earlier iterations. Eowyn Greeno mentioned her work with students on the Zimbabwe program in this context:

I feel the Fieldbook is an excellent assessment tool but I do know some students felt it was a little too 'personal' to be the basis for an entive (sic) course grade... Since much of the writing is based on personal experience and opinion (which is of course the beauty of the Fieldbook) there is a lot of difficulty in giving grades ... there is no such thing as a completely objective grade, but I had too many 'discussions' with students about individual assignment grades to leave this comment out. (FBS, Item 5)

However, as the technique has evolved, we have worked out clearer learning objectives for each dimension of the Fieldbook and guidelines for assessing them. The result has been a reduction in the number of objections, and less frequent and strenuous challenges to its legitimacy as an evaluation instrument. Indeed, it is noteworthy that only a few of the staff, in responding to the survey, cited grading as a major or continuing problem in using the Fieldbook. Where grading questions do occur, however, and where they have spilled over to become more serious disputes that have required the adjudication of the Pitzer External Studies Office, other issues are likely to be involved. We discuss two such issues below, namely, disparities in student writing skills and problems in responding to inappropriate cultural behavior when it appears in Fieldbook assignments.

\section{(3) Student Writing Skills}

Study abroad programs, like colleges and universities in general, attract students with varying academic skills and intellectual capacities. It may also be said that in most cases students who are better prepared in traditional academic skills, like certain types of writing and thinking, have a greater chance of earning better grades than those who are less well prepared. That said, it is evident to many that neither strong writing skills nor the grades they may earn are indications necessarily that one student has learned more from an assignment than another whose skills are 
weaker and who might have received a lower grade than their colleague. The problem here is one that is endemic to evaluation and grading in the broader sense: do we use feedback and grades formatively to induce learning, or summatively to judge it as a finished product?

Some of those who have worked with the Fieldbook regard evaluation more in the summative fashion and believe an advantage is given to students who are already good writers and clear thinkers. In Venezuela, Karen and Eduardo Rodriguez observed that the Fieldbook works "for the good writers. For weaker writers, it's not perfect":

You either have to stretch and interpret for them what you think they were saying, or you penalize them for poor writing when in fact they may be better 'immersers.' The Fieldbook also works well for those who want to think reflexively and process via writing. For those who just want to throw out the answer and not really engage, it is still easy to write a 'good' Fieldbook that has little meaning. It seems fairly easy for students to guess what we hope to hear, so the challenge has to come more from a desire to dig deep into themselves. Not everyone wants to do that. (FBS, Item 4)

Similarly, Francis sees the differences in writing ability as the "primary drawback to the Fieldbook" because:

Not all students are great writers and therefore may have difficulty documenting and expressing in writing all that they have truly learned. A student who received consistently 19 out of 20 points on their Fieldbook entries did not necessarily learn or gain more from the experience than a student who received 14 out of 20. (FBS, Item 4, emphasis in the original)

It would seem that there are at least two questions being raised here: first, is the Fieldbook concerned more with measuring effective writing and thinking than with what is being learned through the experience; and, second, is there a way to eliminate some of the bias that may be diminishing the grades of poorer writers and allowing better writers to succeed glibly?

The first question is easier to address, inasmuch as educational goals for the Fieldbook clearly seek to promote critical thinking and writing skills and other sorts of skills and knowledge related to intercultural 
understanding. More difficult to get at is how (or whether) grading criteria should be rebalanced to assure that more learning takes place and is graded appropriately and in a more formative manner. Here, issues of staff training, the mix of low-stake and high-stake assignments, and the institutional needs of sending schools are all factors to be considered.

Finally, it is important to remember that writing ability is an issue for the Fieldbook quite apart from questions of grading and evaluation. Whatever approach is employed to assess and support students, some will come to the program with stronger skills than others (especially including those who have writing-related learning disabilities). For staff, this has meant finding ways to offer help to those who need it, and recognizing that those students have added pressure to keep up with Fieldbook assignments and other program work. Lisa Ferrante-Perrone, the coordinator of the Pitzer in Italy's Modena site, describes such a situation:

I ... recall one student whose weak writing skills hindered her in her Fieldbook assignments. I worked with her along with the program director, and we encouraged her to rework her assignments and to submit them a second time for evaluation. This meant that she often had a backup entry to complete along with the one that was due the following week, which was a bit stressful for her at times, I believe. The Fieldbook can be intimidating for students who aren't very comfortable with their writing skills (though it can improve their skills, as well). (FBS, Item 5)

Ferrante-Perrone's last point is, of course, most critical, and represents one of the real measures of the Fieldbook's success with respect to fostering more effective written expression.

\section{(4) Cultural Sensitivity and the Fieldbook}

Without a doubt, one of the most complicated issues that the Fieldbook presents to us as educators is whether, when, how and where to respond to instances of student ethnocentrisms. The different and often conflicting values among students and staff about what is and isn't sensitive, true, fair, and proper are informed by culture, age, education, religion, gender, politics, class, nationality, race, and probably many more factors as well. For example, a staff member from the host culture might 
be offended by a style of communication that he deemed too informal, but that a staff member from the US understood differently. Or, it is likely that in their initial experience with Fieldbook entries, host culture representatives may find student observations or remarks about the culture to be upsetting. Franca Feboli in Italy explains:

I felt sometimes, especially at the beginning, burt by what my students were writing about MY culture but then I started thinking that this was also helping me to see my own country and culture through different eyes. (FBS, Item 3)

Dengu-Zvobgo in Zimbabwe recalled often wanting to take issue with student observations, and the Rodriguezes of the Venezuela program, who are from the US and Mexico respectively, found themselves at times taking umbrage at comments that seemed to implicate Latin America in a negative fashion.

More seriously, some students revealed viewpoints, unsubstantiated by evidence, which struck staff readers as egregiously ethnocentric and at odds with the educational goals of the program. This was problematic because the development of intercultural understanding and the ability to function sensitively within other cultures are explicit goals of Pitzer programs and underlying objectives for the study abroad experience in general. In terms of the particular goals of the Fieldbook, developing intercultural skills and knowledge is supported in a number of ways through assignments designed to help students cultivate their abilities to make "nonjudgmental observations" about the host culture as they seek affectively and cognitively to appreciate points of view different from their own.

Here, two examples, both from Zimbabwe/Botswana, may serve to illustrate. The first deals with a student story written in Botswana that contained a good deal of raw and sexually explicit language that the program staff members found personally and culturally offensive. The student was asked to "sanitize" the story and complied, but for the staff it remained problematic and raised the larger question of whether in all elements of the Fieldbook students shouldn't be asked to observe or at least be sensitive to local values and mores. In the aspects of the Fieldbook that allow for more creative expression, the addition of hard and fast rules to govern language and modes of expression might prove stifling and create 
greater tension over assignments. On the other hand, as a principal goal of the program is to develop the student's sense of cultural awareness and understanding, not offering guidance or feedback at times when student's behavior (including their language use) is inappropriate would be irresponsible on the part of staff.

The second example of cultural conflict over a Fieldbook assignment is related by Greeno from the Zimbabwe program, about a Focus Question dealing with the impact of economic development and globalization on rural Zimbabwean communities and their members. Another staff member, Sondy Yodelman, initially graded the question:

On the awful end, one focus question stands out (for its) very ethnocentric tones... The student wrote a response based almost completely on his own opinion about Zimbabwean society that lacked any evidence of sensitivity to local culture or development realities. Sondy was so offended ... that she asked both Kebokile and me to read the essay to gange our responses. We all agreed the student should receive a low mark according to our grading criteria because we felt he had not fully examined the issue nor had he included any information from interviews, etc. However, we all also very clearly and personally disagreed with the student's opinions. Sondy returned the essay (along with a very well thought out response and questions for further thought) with a lower than normal mark. The student was furious at receiving a low mark and insisted that Sondy was simply punishing him for having a different point of view than her own. This did provide us with an opportunity to try and address some of the misguided conclusions we felt he was making about the local situation but I would have to say the overall outcome of this type of scenario (and I can't say this was completely an isolated incident) was negative as it led to a 'me vs. them' feeling regarding the program staff on this student's part. (FBS, Item 5)

While the student's failure to comply with the basic requirements of the assignment make the response of staff members simple to justify, that they took extra pain and care to separate the reasons for the lower grade from the disagreement over the student's opinions, reveals the tension which exists when we must sort through judgments (our own and others) about reality. The desire to want to minimize this tension and keep it from spilling over into "us and them" divisions is understandable, but 
should not be allowed to obviate (and in this case it did not) the responsibility to challenge the ethnocentrism and misjudgments of our students and our colleagues. Helping the staff members, especially younger ones, to become comfortable in this role is indispensable to the success of a teaching tool like the Fieldbook.

\section{(5) Student Centeredness and Empowerment in the Fieldbook}

In its design, the Fieldbook was conceived as a learning and evaluative technique that could respond to the educational needs of students on experiential-based study abroad programs. Compared to traditional study abroad, these "field" programs were and are more focused on the studentdriven learning. They are informed, in Pitzer's case at least, by principles of constructivist teaching and cooperative learning, and they intentionally try to move away from teacher-centered models of instruction. The structure of Fieldbook assignments, the variety of writing styles it employs, the emphasis that it places on the student as a gatherer and producer of knowledge, all speak to some degree of it being student-centered.

And yet compared to other pedagogical approaches, especially those popularized under the banner of Paolo Freire (1970) and others, the Fieldbook remains somewhat detached from the student. Assignments are designed and scheduled by staff, and even though a great effort is made to assure that the questions posed will be relevant to the student's experience, the fact that students are not participating in shaping at least some of those questions may be reducing the ultimate effectiveness of the Fieldbook. Staff members from several programs, including Botswana, Zimbabwe, Venezuela, and Turkey, have indicated a desire to "empower" students more fully to author Fieldbook assignments. The staff in Turkey, as we have pointed out, is considering allowing students to undertake mini research projects in lieu of DYO assignments. From Botswana the suggestion was made to allow students to have a design-your-own component for the Focus Questions. Dengu-Zvobgo, however, takes a slightly different take:

I would like to see students being more involved in deciding one or two of the Focus Questions as a group, not individually. This is empower- 
ing and would expand the FB and indicate that we indeed believe that the students are capable of making this contribution. (FBS, Item 8)

By working with the student group, field staff would be able to engage in the dialogic process that Freire (1970), Ira Schor (1992) and others see as essential to empowerment learning. Such thinking, translated more broadly to all aspects of the Fieldbook, will help to assure its continued development and refinement as a learning tool for both students and teachers.

\section{Conclusion}

If study abroad education is intended to promote learning about culture, then our effort must be to understand better what resources and strategies we as educators need to develop and deploy for students to be successful in that learning. Applied research on pedagogy and other aspects of the study abroad experience can contribute in critical ways to improving such understanding. Case studies of different pedagogies and approaches can enrich our understanding of what constitute best practices and suggest new directions for the future.

This case study of the Pitzer College Fieldbook, though only one small example of this kind of applied research, opens a window into the process of creating and adapting study abroad pedagogy that responds to the learning needs of students. Students and staff alike have found the Fieldbook to be a very useful educational too, albeit one that requires continual refinement.

We believe the Fieldbook's utility may extend beyond the boundaries of study abroad programs. The approach might be adapted for other educational purposes, such as internships and community-based learning programs, which have significant field study elements. In such cases, Fieldbook assignments might be designed to facilitate student learning around issues of social responsibility and engaged citizenship or other educational objectives.

The subject matter focus and integrative philosophy of the Fieldbook could also accommodate a more comprehensive set of educational purposes, helping students to demonstrate intellectual competencies over and within a range of disciplines and problems. Comparing dif- 
ferences in writing quality and/or student learning among different programs and portfolio approaches would help individuals and institutions to choose pedagogical strategies that best respond to their learning needs and educational goals. It was, in fact, out of just such a situation that the Fieldbook was developed over a decade ago and from which it continues to evolve, shaped by the imagination, needs and collaborative energies of the teachers and students who have used it.

\section{Notes}

1 Pitzer's programs tend to emphasize intensive language study, homestays with families, independent study and an interdisciplinary course on aspects of the local, regional and/or national culture.

2 The survey was sent to twenty current and former staff members, some of whom had been former students. Nineteen people responded.

3 The Letters Home also provide valuable information on students' adjustment process and changing perceptions to the Fieldbook reader or program administrator.

${ }^{4}$ East China Normal University in Shanghai.

5 A response from the reader of this entry in the margin of the Fieldbook notes that the author has this point wrong and that there are common toilets in the dorms; however, the cleanliness by US student standards is not disputed.

6 Meaning even if they came with no Italian language skills.

7 In the Fall 2000, owing to deteriorating political and economic conditions in Zimbabwe, Pitzer relocated its program to neighboring Botswana.

\section{References}

Elbow, Peter. Everyone Can Write. New York: Oxford University Press, 2000.

Freire, Paolo. Pedagogy of the Oppressed. New York: Continuum, 1970.

Fulwiler, Tony. "Writing Back and Forth: Class Letters." Writing to Learn: Strategies for Assigning and Responding to Writing Across the Disciplines: 
New Directions for Teaching and Learning. Eds. M.D. Sorcinelli and P. Elbow. San Francisco, CA: Jossey Bass, 1988.

Merriam, S.B. Qualitative Research and Case Study Applications in Education. San Francisco, CA: Jossey Bass, 1998.

Schor, Ira. Empowering Education. Chicago, IL: University of Chicago Press, 1992.

Taylor, N. The travel journal: An assessment tool for overseas study. New York: Council on International Education Exchange (CIEE), 1991.

Wagner, K., and T. Magistrale. Writing across culture: An introduction to study abroad and the writing process. New York: Peter Lang Publishing, 1995. 